\title{
Stability analysis and treatment measures of rainfall-induced landslides in Ningzhen area : A case study from Yongning town in Pukou district, Nanjing city
}

\author{
Ping Sun ${ }^{1, a}$, Tao Xue ${ }^{2, b}$ and Mingxue Jiang ${ }^{3, c^{*}}$ \\ ${ }^{1}$ Jinling Institute of Technology, Hongjing Road Jiangning District of Nanjing No. 99, China \\ ${ }^{2}$ Jinling Institute of Technology, Hongjing Road Jiangning District of Nanjing No. 99, China \\ ${ }^{3}$ Guangxi College of Water Resources and Electric Power, Changgang Road Xingning District of \\ Nanning No. 99, China \\ a sunping@jit.edu.cn, ${ }^{b}$ xuetao@jit.edu.cn, ${ }^{c}$ jone10@foxmail.com
}

Keywords: Xiashu loess; rainfall; landslides; shear strength.

Abstract. The main soil types in Ningzhen area is Xiashu loess which has special geology characteristic that vary significantly based on different level of water content. This paper intends to analyze causes of the landslide took place in Yongning town and find out how Xiashu loess becomes vulnerable under the action of rainfall. In order to evaluate the stability of a slope where landslide has occurred every year since 2010 and to prevent further damage, a series of test were performed and a method of random and fuzzy reliability analysis was introduced to determine relationship between water content and other factors that affect the probability of failure of soil, such as safety factor, shear stress and human activities.

\section{Introduction}

Xiashu loess is a special deposit that underwent weathering and formed in Late Quaternary Pleistocene, mainly distributed in the region of the middle and lower reaches of the Yangtze River [1]. The Brown clayey widespread over the region of Nanjing and Zhenjiang area and was named Xiashu series by Siguang Li and Sen Zhu in 1935 [2, 3]. The typical geological profiles are those across areas such as the Taishan Nanjing New Village, the Swallow Rocky, the Tiger Mountain and the Zhenjiang Port.

Stability of Xiashu soil can be considerably affected by rainfall [4]. Xiashu loess has developed vertical joints and nonintegrated contact with the underlying bedrock where exhibit various properties. A phenomenon of viscous flow can be found when groundwater reaches the contact surface, which creates a weak interlayer causing instability of slope as a result of long-term immersion [5].

The frequent occurrence of landslides have been attached great importance by the local authorities, many treatment measures have been taken to prevent the occurrence of landslide, however, because of its sudden and unpredictable nature, landslide is still seriously affecting people's life and safety.

\section{Terrain and Geomorphology}

The mountain landslide which is in the accelerating creep stage is located at the foot of the Laoshan Mountain in Yongning town, its geomorphology is hillslopes, the overall terrain southwest to northeast is high-low, center point coordinates: longitude 118 degrees 35 '27.94 'E, latitude 32 degrees 07' 02.80 "N. The region has plenty of rainfall, and annual average rainy days are 117 days, the rainfall amount is $1106.5 \mathrm{~mm}$, half of which takes place during period from June to September. From 2007, the landslide takes place every year in rainy season. The extension of the landslide is developing from 2010 to date, the length of landslide body is up to 10 meters in roughly " $\mathrm{U}$ " - shaped from a plane view. The entire landslide area is about $4800 \mathrm{~m}^{2}$ and the volume of landslide body is about $24000 \mathrm{~m}^{3}$. The elevation of front and the trailing edge is about $57.00 \mathrm{~m}$ and $88.00 \mathrm{~m}$ respectively, the slope is about 25 to 30 degree and the slope length is about $95 \mathrm{~m}$. 


\section{Composition and Character of Soil}

In this case, the soil belongs to the Late Quaternary Pleistocene deposit. According to their structural character, properties and difference of physical and mechanical character, the soil can be divided into 6 layers, see Table 1.

Table 1 Composition of soil

\begin{tabular}{lllll}
\hline Stratum No. & Stratum Name & color & compression ratio & distributing \\
\hline 1 & filled construction waste & variegated & uneven & all over \\
2 & filled soil & grey yellow & uneven & all over \\
3 & silty clay & brown yellow & medium & all over \\
4 & eluvial soil & brown yellow & medium & all over \\
5 & rubble soil & variegated & uneven & all over \\
6 & weathering mudstone & mulberry & low & all over \\
\hline
\end{tabular}

\section{Landslide type.}

In accordance with the soil composition, causes, forms and other indicators, the slide can be divided into the following five categories, as shown in Table 2.

Table 2 Landslide classification

\begin{tabular}{lll}
\hline No. & in accordance with & \multicolumn{1}{c}{ categories } \\
\hline 1 & soil Mass Properties & clay landside \\
2 & thickness & shallow landslide \\
3 & causes & rainstorm -induced \\
4 & mechanical properties & active landslide \\
\hline
\end{tabular}

\section{Influence factors}

The first factor is terrain and Geomorphology.

The second one is surface water and groundwater. The landslide takes place in the piedmont slope area, where lush vegetation causes surface infiltration since vegetation makes surface water flow changes in speed from fast to slow. Survey showed that the Xiashu soil in the slide body, mainly distributes over the bedrock surface, has a high tendency to expand and the free expansion rate is $73.3 \%$. It is very easy for this kind of soil to collapse and soften since it is easy to dissolve in water and thus form a weak structural plane. The vertical joints in the soil can reach a depth up to 2 to $4 \mathrm{~m}$, cracks make it much easier for water to infiltrate into underground. The soil expands under the effort of water, which reduces shear strength and increases the weight. With the decrease of the resist slippery strength and the increase of the sliding force, the stability of the slope is degraded and the failure is finally occurred. Most of landslides formed by traction of multiple slide bodies.

The final factor is human activities. Human engineering activities frequently takes place in the slide are activities such as the construction of temporary roads and the excavation in the front edge of the landslide, which make free face at the slope toe.

\section{Correlation test between water content and shear strength}

The sample used in the test were taken from the site and should be dry, smashed, sieved to make sure that the original structure is completely destroyed. The soil samples were sealed with different rate of water content, and after stewing 24 hours can Proctor compaction tests be performed. The physical and mechanical properties of the test were measured under different water content conditions, results shown in Table 3. 
Table 3 The physical and mechanical properties of Xiashu loess

\begin{tabular}{ccccc}
\hline $\begin{array}{c}\text { sample } \\
\text { No. }\end{array}$ & water content & $\begin{array}{c}\text { density } \\
{[\mathrm{g} / \mathrm{cm} 3]}\end{array}$ & $\begin{array}{c}\text { Cohesive force } \\
{[\mathrm{kPa}]}\end{array}$ & angle of internal friction [ ] \\
\hline 1 & 17.7 & 1.98 & 77.1 & 18.6 \\
2 & 15.1 & 1.86 & 89.3 & 23.5 \\
3 & 11.7 & 1.83 & 91.7 & 29.2 \\
4 & 9.1 & 1.79 & 123.2 & 30 \\
5 & 6.9 & 1.70 & 178.5 & 39 \\
\hline
\end{tabular}

The change of water content has a great influence on the stability of soil, as can be seen from the experimental results that the cohesive force and the internal friction angle are obviously decrease as the water content increases. There are two reasons, firstly, the increase of water content increases pore water pressure and decreases effective stress, which leads to the reduction of soil shear strength. Secondly, the increasing osmotic force of water can reduce the stability of the slope.

Aimin Han made use of the three axis test to study the strength of the soil structure in Nanjing. Her results also confirmed that the water content of soil has a significant effect on the structure strength of the soil. The structure strength of soil decreases as the water content increase (Eq. 1) [6].

$$
\mathrm{q}_{\mathrm{s}}=25182.9 \mathrm{e}^{-0.278229 \omega}
$$

\section{Reliability analysis of slope stability affected by water}

Based on the fuzzy random reliability analysis method, the influence of water on the stability of slope under wet condition were compared with that under dry condition [7], the results were shown in Table 4.

Table 4 Comparison and analysis of the effect of water on slope stability

\begin{tabular}{|c|c|c|c|c|c|c|}
\hline \multirow[b]{2}{*}{$\begin{array}{l}\text { The slope } \\
\text { condition }\end{array}$} & \multicolumn{3}{|c|}{ dry condition } & \multicolumn{3}{|c|}{ wet condition } \\
\hline & $\begin{array}{l}\text { mean of } \\
\text { safty factor }\end{array}$ & reliability & $\begin{array}{l}\text { probability of } \\
\text { failiure [\%] }\end{array}$ & $\begin{array}{l}\text { mean of safty } \\
\text { factor }\end{array}$ & relaibility & $\begin{array}{l}\text { possibility } \\
\text { of failiure } \\
{[\%]}\end{array}$ \\
\hline results & 1.4384 & 3.1114 & 0.093 & 1.2054 & 1.7074 & 4.391 \\
\hline
\end{tabular}

The water is extremely unfavorable to the stability of the slope. although there is little difference between the safety factor of the slope under the condition of dry and of wet, the slope under wet condition is almost half the reliability of that under the dry condition, the damage probability increases sharply as water content increases.

\section{Treatment measures}

The landslide is about $3 \sim 5 \mathrm{~m}$ in thickness, which belongs to the shallow landslide. The whole slope body is divided into two landslide bodies by a temporary road, the upper part and the lower part are treated respectively. Using the combination of anti-slide pile, retaining wall and intercepted drain system, namely setting anti-slide pile in both part of landslide, Mortar masonry retaining wall (as shown in Fig. 1) at the foot of the slope to prevent soil loss.

The elevation of artificially excavating holed anti-slide pile in the upper part was $72.6 \mathrm{~m}$ and $60.1 \mathrm{~m}$ of that in the lower part, pile section size is $1500 \mathrm{~mm} \times 1000 \mathrm{~mm}$. The section size of Cap beam is $1800 \mathrm{~mm}$ by $1000 \mathrm{~mm}$ and the long axis direction of the pile is consistent with the landslide direction.

The following measures has been taken in addition to the above mentioned: 
The drainage system is adopted in the upper part of the slope that was divided by the temporary fire road. A drainage ditch was set along the road that extend to the foot of the mountain, connecting to roadside flood intercepting trench.

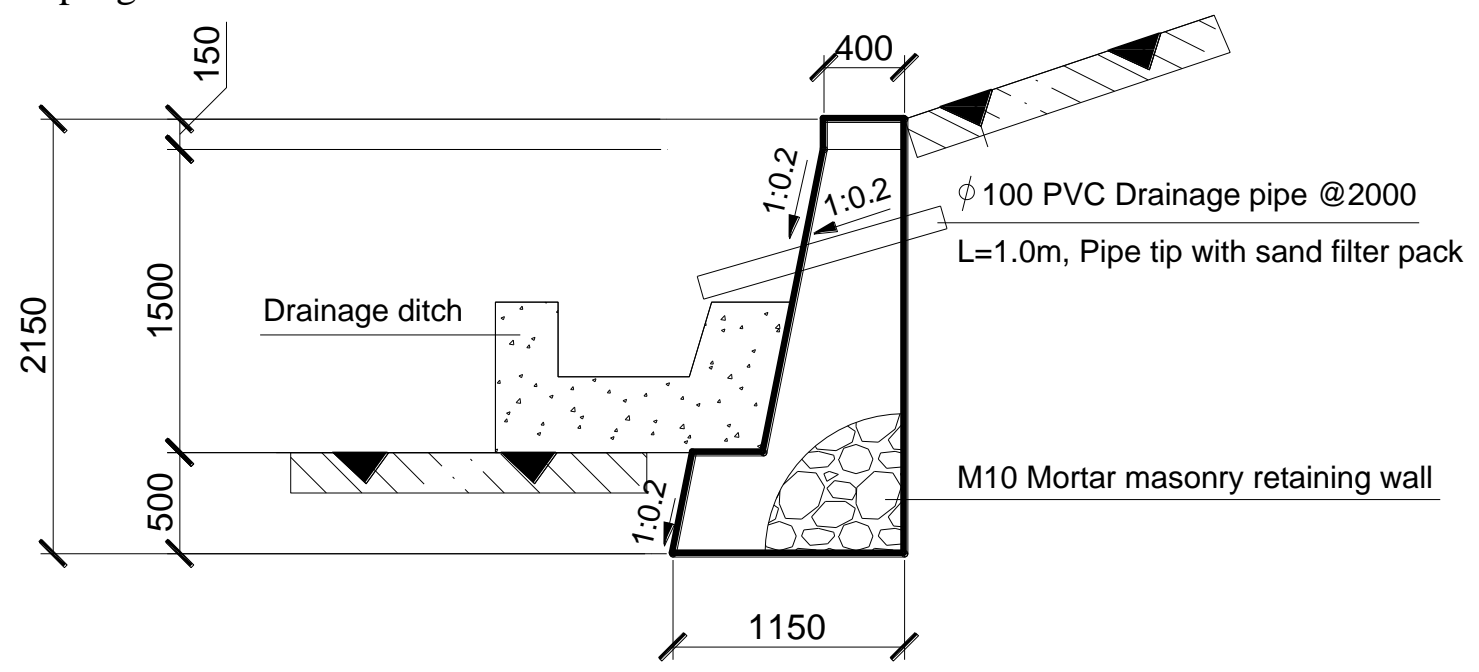

Fig.1 Mortar masonry retaining wall

\section{Conclusion}

The combined effects of rainfall infiltration and groundwater cause the sliding force to increase, and shear strength as well as the friction to decrease, leading to the sharp increase in the probability of the failure of the slope soil. Rainfall is the key factor in the landslide of Xiashu.

\section{References}

[1] Le Pingdeng, Xuefeng $\mathrm{Hu}$, Xiaoming Fang. A review of the research on the formation of the Loess in the middle and lower reaches of the Yangtze River [J]. Bulletin of mineralogy, petrology and geochemistry. 2002,21(1):54-57. In Chinese.

[2] Jianjun Cao. Suction characteristics and application of the soil suction in the area of the town of Ning Zhen[D]. Master Thesis of Hohai University. 2007

[3] Hongjun Yu. New exploration on the causes of the East China Continental loess [J]. Quaternary Sciences. 1999(4):366-372.

[4] Jing Chong, Xusheng Li, Dayuan Yang. Geological hazard of slope in Zhenjiang city and Its Control Countermeasures[J]. Journal of Catastrophology. 2002,17(1):20-25.

[5] Jing Li. Study on Regional Forecasting and forecasting of the landslide area in the area of Nanjing[D]. Master Thesis of Hohai University. 2006:28.

[6] Aiming Han, Chunyuan Qiao, Changyang Ding. Study on the strength of Xiashu loess in Nanjing[J]. Journal of Engineering Geology. 2009,03:371-376.

[7] Wenhui Tan, Meifeng Cai. The generalized reliability theory and practice of slope engineering. China Science Publication, 2010. 